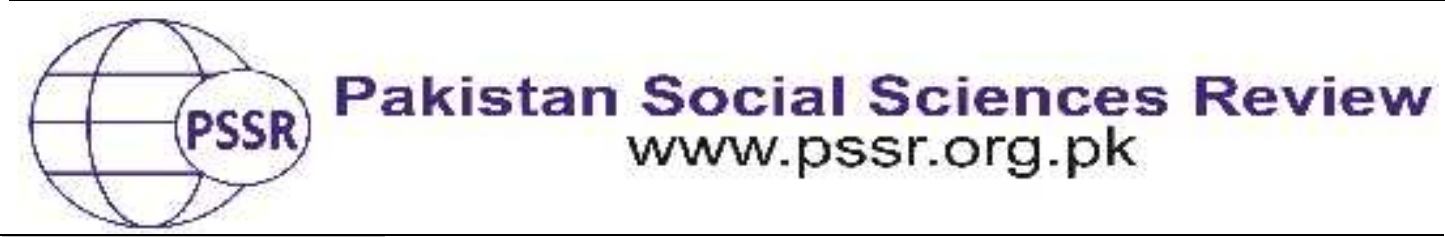

RESEARCH PAPER

\title{
Social Media Use and Infodemic Perception of Adults during Covid-19
}

\author{
Dr. Muhammad Rashid Khan ${ }^{1}$ Zunaira Mir ${ }^{2}$ Ayesha Jahan Lodhi ${ }^{3}$
}

1. Assistant Professor, Institute of Communication Studies, University of the Punjab, Lahore, Punjab, Pakistan

2. M. Phil Communication Studies, Institute of Communication Studies, University of the Punjab, Lahore, Punjab, Pakistan

3. Lecturer, School of Integrated Social Sciences, University of Lahore, Lahore, Punjab, Pakistan

\begin{tabular}{|c|c|}
\hline PAP & \\
\hline $\begin{array}{l}\text { Recei } \\
\text { Octobe }\end{array}$ & $\begin{array}{l}\text { of } \\
\text { ing }\end{array}$ \\
\hline 2021 & $\begin{array}{l}\text { COVID-19 in Lahore. } 260 \text { students and profe } \\
\text { participants were selected for the research out of which } \\
\text { males and } 172 \text { were females from different governm }\end{array}$ \\
\hline $\begin{array}{l}\text { COI } \\
\text { Info } \\
\text { Perc } \\
\text { Inst } \\
\text { Soci }\end{array}$ & $\begin{array}{l}\text { private colleges and universities of Lahore. Statistical package } \\
\text { for social sciences (SPSS version 21) software was used to } \\
\text { analyze data in the form descriptive frequency and standard } \\
\text { deviation. Relationship between Instagram use and social } \\
\text { interaction, personal identity, entrainment and quality of } \\
\text { information about Covid-19 were analyzed using Pearson } \\
\text { product moment correlation analysis. Results revealed }\end{array}$ \\
\hline $\begin{array}{l}\text { *Corres } \\
\text { Author }\end{array}$ & $\begin{array}{l}\text { nd social interaction, individual identity, diverse behavior, } \\
\text { tainment trends and updates of Covid-19 was approved as } \\
\text { 01). }\end{array}$ \\
\hline
\end{tabular}

\section{Introduction}

In this digitized world most of the adults have been relying on the entertaining content on Instagram and other social media applications to either catch up with their old fellows or just to boost up their self-worth by getting approval of their social media audience. Studies verifying $71 \%$ of young people between the ages of 18 and 24 are now Instagram users. There is a huge fluctuation seen in the consumption of entertainment and news content during the times of COVID-19. Users of Instagram usually have set pattern of objectives linked with the needs and motives. Being young, students are gratified through exposure to different types of 
content on Instagram which influence their behavior, perception, activities patterns and interests (Huang \& Su, 2018).

Instagram contains almost every type of content of different field of expertise, entertainments, health and fitness, beauty and clothing. Instagram has been serving as a gratifying bridge between the user and their needs. Researcher argued the types of gratifications 'instant gratification' and 'deferred gratification' while users of social media sites generally want instant gratification related to their instant urge for change adopted by others (Oloo, 2013). Studies are exploring the relationship between rate of individual's exposure to media content and gratification of their need to change attitude for personal identities and perception of entertainment. People also tend to gratify their needs by posing and posting fake information, unreal experiences and fake stories to gain public attention in real life. People with worthless personalities often have history of loneliness and lack of satisfaction in their life. Those people when found social media platform i.e. Instagram, they started using it as a tool of their satisfaction by gaining public attention and response to their actions (Ruggiero, 2000).

Discussions of the obsession towards physical appearance in the times of COVID-19 found to be popular on Instagram. Instagram is already all about communication through pictures where physical appearance, colors and creativity speaks. Furthermore, manipulation of pictures, self-projection and obsessive behavior towards physical appearance is common. Due to the imposed lockdown in Lahore in order to avoid the spread of Corona Virus use of Instagram increased because people were avoiding face to face interaction. Instead they post pictures more often and share Instagram stories on daily basis in order to keep people updated. One the upcoming trends on Instagram, blogging are the trendiest in which bloggers usually share their routine activities, experiences, and life stories to catch follower's attention.Along with the social interaction, Instagram has also been used widely for electronic shopping and digital marketing. During the imposed lockdown in different areas of Lahore easy access to food was limited (Hamilton et al., 2020).

Wagner et al. (2020) explains the art of making immunity as a unique selling point for various articles during the time of COVID-19 by observing the hash tags that are used regarding health. Around the world, two-thirds (66.1\%) of Instagram users use COVID-19 and corona virus as hash tags to disperse the information related to COVID-19. Moreover, reliable sources like World Health Organization (WHO) and Centers for Disease Control and Prevention (CDC) have also been using Instagram and other social media deals in order to keep people updated about Covid-19. Since the day lockdown was imposed in Lahore all the young adults have been depending on the internet whether for the sake of their online classes, assignments, work from home or socializing with their friends and family as it is the only source to keep the life functional (Rovetta \& Bhagvathula, 2020).

It was observed that sociological perspective objective criteria for a crisis only really take on meaning when they are perceived and interpreted. Humans as social 
animal perceive whatever they consume on Instagram or any other social media platform and it influences their behavior and patterns. Information absorbing from social media network Instagram may cause to develop wrong perception about important phenomenon of life (Reetz et al., 2020). In this context, where communication majorly takes place online through social media, it is important to analyze behaviors and attitudes that people opt to communicate in order to give a valid justification about socializing procedure over social media applications such as Instagram. The research framework of this study is based on internet addiction and the uses and gratification theory. Most research on internet addiction is based on initial research of young (Young, 1998).

\section{Internet Addiction}

Internet addiction is described as a state where an individual has lost control of the internet use and keeps using internet excessively to the point where he/she experiences problematic outcomes that negatively affects his/her life (Young \& Abreu, 2011). Internet addiction is a global issue, and occurs when too many people use their smart phones in a variety of ways for excessive amount of time. During the times of COVID-19 use of Instagram has also increased due to the imposed lockdowns all over the Lahore. Entertainment and social interaction sources are strictly bounded to Internet and social media sites alone. Instagram is acting as a source of diversion and providing an escape to cope up with the change in the routine of young adults.

\section{Uses and gratifications theory}

The Uses and Gratification Theory signifies the relationship between the audience of Instagram and their tendencies of content consumption gaining through different entertainment trends on Instagram. Moreover, it separates the media consumption motives as gratification to their personal identities and abilities of selfmotivation. It shows how our needs for media consumption may have an impact on the effects of media disclosure. COVID-19 has generated different types of needs and motivations in Instagram users to be gratified within impulsive ways. Students usually visit Instagram to entertain themselves and cheering up to reduce frustration. The urge for the gratification to be achieved tends in increasing ascompared to the normal routines before COVID-19 (Katz \&Blumler, 1973).

\section{Objectives of the Study}

The present study has following objectives:

- To find the role of social media (Instagram) use in increasing the perceptions of social interactions among adults during lock down.

- To find the relationship between Instagram use and perceptions of entertainment trends influenced byroutine activities of celebrities on Instagram. 
- To find out nature of relationship between use of Instagram and quality of information related to causes, transmission and precautions of Covid-19.

- To evaluate the predicting role of average time spend in browsing Instagram daily for individuals identity, entertainment trends and level of social interaction among adults.

- To find the relationship between Instagram use and personal identities, interest, motives and action that influenced by Instagram users.

\section{Hypothesis of the Study}

\section{Hypothesis of Correlation}

- There will be positive relationship between Instagram use and social interaction of participants.

- There will be significant positive relationship between Instagram use and perceptions of individual identity.

- There will be positive relationship between tendencies of Instagram use and diverse behavior of its users.

- There will be significant positive relationship between Infodemic perceptions of Instagram users and their entertainment trends.

- There will be positive relationship between Instagram use and information of causes and transmission procedure of COVID-19.

\section{Hypothesis of Prediction}

- Average time spend using Instagram would likely to predict Infodemic perception of adults during Covid-19

- Excessive use of Instagram would likely to predict social interaction in participants

- Instagram use would predict entertainment trends and individuals identity.

\section{Proposed Model of Correlation}

Proposed model of Correlation b/w needs/ motives of using Instagram and aspects of individual's life during pandemic situation in Lahore. 


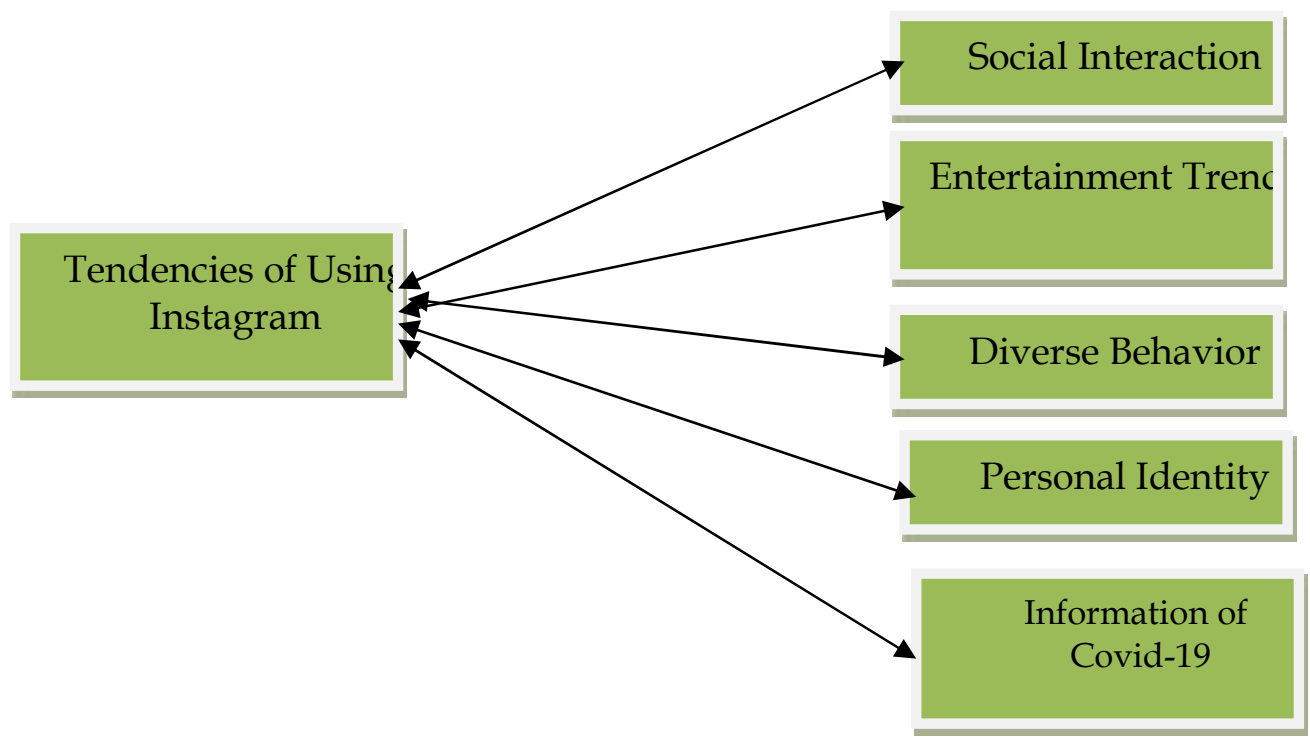

\section{Proposed Model of Prediction}

Proposed model of prediction of Instagram use and Individual's behavior during COVID situation in Lahore.

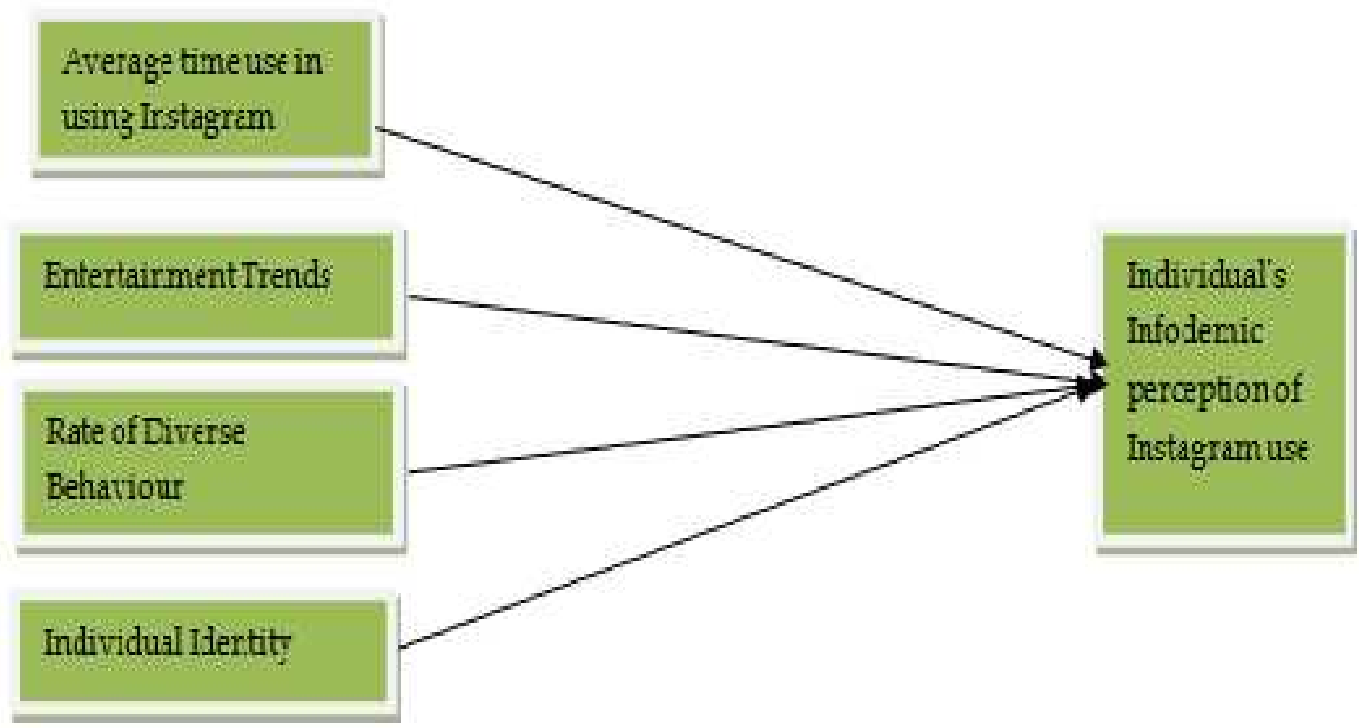

\section{Material and Methods}

Given research study was aimed to explore individuals Infodemic perception influenced by social media use during pandemic situation of COVID-19 in Lahore. Participant interest in Instagram use and its effects on their social interactions, 
personal identity, updates of Covid-19 situation and entertainment purposes was explored.

\section{Research Design}

Experimental research design was used to evaluate effects of Instagram uses on social interaction, individuals personal interest and identities, updates of Covid19 and diverse behaviors among male and females during pandemic situation.

\section{Sample Size/ Sample techniques}

Total 260 students and professionals participants were selected for the research, out of them 87 were males and 172 were females from different government and private colleges and universities of Lahore. Age of participants was ranged 17-50 years. Rationale of selection sample of the research was their tendencies of using Instagram and other social sites for their educational and entertainment purposes. Non probability purposive sampling techniques were used for data collection. This sampling method was used because it can help in generalization of the sample and findings from the research. Respondents in this research were selected on bases of previous literature.

\section{Instruments} participants

Given instruments and questionnaires were used to collect data from

\section{Personal Information Sheet}

Personal information sheet was used to collect major demographics of participants including their age, gender, occupation, education and marital status. Participants average time spend on using Instagram was also collect to evaluate its moderating effects on their diverse behavior and quality of information sought by using Instagram. Moreover, major descriptive and means for demographic characteristics were generated. Responses from participants were collected in form of scalar, nominal and categorical variables.

\section{Tendencies of Using Instagram Scales (TUIS)}

Tendencies of using Instagram scale was developed by researcher to find effectiveness of Instagram use and need and motives behind excessive use of Instagram. Scale was consisted of 28 items on five point Likert scales ranging (Strongly disagree=1-strongly agree $=5$ ) measuring social interaction, diverse behavior, entertainment purposes, personal identity and information of covid-19. Scale had 6 subscales measuring different needs and motives of individuals using Instagram and their average time of using Instagram. Scale was reviewed and was pretested on sample of 50 participants to check validity and reliability of the scale. 


\section{Procedure}

Proper procedures of taking permissions were followed both from university and institutes from where data was collected for research purposes. Participant's behavior of using Instagram was asked prior to give them questionnaire. Participants were debriefed about purposes and procedure of the research along with value of their participation and responses. Consent form was signed by the participants to ensure their information should be kept confidential during and after research study. Personal information was collected using demographic sheet and difficult terminologies were explained to participants where needed. Participants' responses were collected carefully and further used for study to evaluate results.

\section{Ethical Considerations}

There were many types of ethical issues which the researcher had to pay attention for successful completion of this project. The most important consideration was linked with the informed consent of the participants. All the participants were informed about the purpose of this research and had given their informed consent to participate in written form and they were not forced to participate. The identity and names of the participants were kept in strict confidentiality, thus meeting the requirements of the policy of ethics of the University.

Participants were debriefed about purpose of research and about generalization of results to take more advanced steps for rural areas. Difficult terminologies were translated in simple language to make them understandable for participants. Participants were free to leave data collection process if he or she was not feel comfortable being part of research. Participants right were not spoiled to fulfill research purpose, instead participants were presented incentives in form of eatables that needed.

\section{Results and Discussion}

Given portion comprises of data analysis and interpretation of data to find out effects of excessive Instagram use by individuals their need and motive behind the use of Instagram in Covid-19 situation in Lahore. Collected data was reviewed carefully and missing values were resolved using Statistical package for social sciences. Responses to each item of constructed scale were analyzed and results were generated. Statistically package for social sciences (SPSS version 21) software was used to analyze data in the form descriptive frequency and standard deviation. Relationship between Instagram use and social interaction, personal identity, entrainment and quality of information about Covid-19 were analyzed using Pearson product moment correlation analysis. Predicting role of average time spends on Instagram use and personal needs and motives were evaluated using regression analysis. Mediating role or average time spends using Instagram and motives of using Instagram were also analyzed by linear regression analysis. 
Table 1

Descriptive Statistics of Gender of Participants

\begin{tabular}{ccc}
\hline Participants & Frequency & Percent \\
\hline Male & 87 & $33 \%$ \\
\hline Female & 172 & $66 \%$ \\
\hline Total & $\mathbf{2 6 0}$ & $\mathbf{1 0 0} \%$ \\
\hline
\end{tabular}

Table 1 indicated that gender responses out of total participants selected for research. The male frequency of respondents is 87 and has percentage of $33 \%$ and female 172 frequencies $66 \%$ showed higher frequencies of females ( $M=1.657$ and $(\mathrm{S} . \mathrm{D} .=.783)$.

Table 2

Descriptive Statistics of Participant's Age

\begin{tabular}{ccc}
\hline Category Responses & Frequency & Percent \\
\hline $17-20$ & 58 & $22.3 \%$ \\
\hline $21-30$ & 191 & $73.4 \%$ \\
\hline $31-50$ & 13 & $5 \%$ \\
\hline Total & $\mathbf{2 6 0}$ & $\mathbf{1 0 0 . 0} \%$ \\
\hline
\end{tabular}

According to the table 2 ages frequency of respondents of coding (17-20) was 58 while percentage of respondents is $22.3 \%$, second age group (21-30) were191 by frequencies and their percentage was $73.4 \%$ which showed higher number of participants in this age group $(M=23.63$, S.D. $=4.48)$.

Table 3

Descriptive Statistics of Participant's Education

\begin{tabular}{ccc}
\hline Category responses & Frequency & Percent \\
\hline Intermediate & 28 & $10.8 \%$ \\
\hline Bachelor & 92 & $35.4 \%$ \\
\hline Masters & 99 & $38.1 \%$ \\
\hline MPhil & 40 & $15.4 \%$ \\
\hline Total & $\mathbf{2 6 0}$ & $\mathbf{1 0 0 . 0} \%$ \\
\hline
\end{tabular}

Table 3 shows that in education of respondents, frequency of intermediate is 28 and had percentage $(10.0 \%)$ showed the lowest number and percentage. Frequency of Masters was 99 and had percentage (38.1\%) showed higher percentage of participants belong Master education group (M=2.57, S.D. $=.890)$.

Table 4

Descriptive Statistics of Marital Status of Participants

\begin{tabular}{ccc}
\hline Response category & Frequency & Percent \\
\hline Single & 210 & $17.0 \%$ \\
\hline Married & 50 & $80.0 \%$ \\
\hline Total & $\mathbf{2 6 0}$ & $\mathbf{1 0 0 . 0} \%$ \\
\hline
\end{tabular}


Table 4 is showing frequencies of marital status of participants. Out of all single participants are 210 and has percentage (80.0\%).Married participants were $50 \mathrm{and}$ had percentage $(20.0 \%)(\mathrm{M}=1.80)$ and $($ S.D. $=.407)$.

Table 5

Descriptive statistics of participant's occupation

\begin{tabular}{ccc}
\hline Responses category & Frequency & Percent \\
\hline Government Job & 7 & $2.7 \%$ \\
\hline Private Job & 42 & $16.2 \%$ \\
\hline Unemployed & 20 & $7.7 \%$ \\
\hline Student & 157 & $60.4 \%$ \\
\hline Others & 33 & $12.7 \%$ \\
\hline Total & $\mathbf{2 6 0}$ & $\mathbf{1 0 0 . 0} \%$ \\
\hline
\end{tabular}

Table 5 shows responses highest category were students and had frequency 157 with a percentage (60\%). Participants with private jobs were 42 and had (16.2 \%) $(\mathrm{M}=3.10$, S.D. $=.938)$.

\section{Pearson Product Moment Correlation Analysis}

Table 6

Pearson Correlation Analysis between Tendencies of Instagram use and Individual Infodemic perception i.e. Social Interaction, Entertainment trends, Personal Identity, Rate of Diverse Behavior and Updates of Covid-19

\begin{tabular}{|c|c|c|c|c|c|c|c|}
\hline & 2 & 3 & 4 & 5 & 6 & $M$ & $S D$ \\
\hline 1.Instagram Use & $.865^{* *}$ & $.709^{* *}$ & $.814^{* *}$ & $.787^{* *}$ & $.83^{* *}$ & 85.4 & 216.5 \\
\hline 2.Social Interaction & & $.509^{* *}$ & $.803^{* *}$ & $.616^{* *}$ & $.698^{* *}$ & 21.9 & 4.47 \\
\hline 3.Entertainment Trends & & & $.432 * *$ & $.617^{* *}$ & $.584^{* *}$ & 9.64 & 2.20 \\
\hline 4.Indvidual Identity & & & & $.454^{* *}$ & $.549^{* *}$ & 23.7 & 5.93 \\
\hline 5.Updates of COVID-19 & & & & & $.698^{* *}$ & 18.7 & 4.49 \\
\hline 6.Rate of Diverse Behavior & & & & & & 15.4 & 3.67 \\
\hline
\end{tabular}

Table 6 showed results of correlation analysis for the following hypothesis.

Evaluated results showed hypothesis of correlation between Instagram use and social interaction, individual identity, diverse behavior, entertainment trends and updates of Covid-19 was approved as value of correlation alpha for all relation wassignificant $(p<0.01)$ which means excessive use of Instagram tend to increase social interaction among other individuals by increasing rate of interpersonal communication. Mean and standard deviation of social interaction, individual identity, diverse behavior, entertainment trends and updates of Covid-19 are given in table 5.6.

\section{Hierarchical Regression Analysis}

Regression analysis was conducted to check the hypothesis of prediction i.e. predicting role of average time spend in using Instagram and towards needs and motives of participant using Instagram. Average time spend using Instagram would likely to predict needs and motives of Instagram users. The hypothesis (i) Excessive 
use of Instagram would likely to predict social interaction in participants (ii) Instagram use would predict entertainment trends and individuals identity and (iii) Average time spend using Instagram would likely to predict needs and motives of Instagram users.

Table 7

Hierarchical Regression Analysis of Instagram Use and Infodemic Perception of Participants

\begin{tabular}{ccc}
\hline & \multicolumn{1}{c}{ Infodemic Perception of Instagram Users } \\
\hline Predictor & $\Delta R^{2}$ & $\beta$ \\
\hline Step 1 & .037 & $.203^{* *}$ \\
\hline Average time spend & & $.141^{* *}$ \\
\hline Step 2 & .782 & $.220^{*}$ \\
\hline Entertainment trends & & $.043^{* *}$ \\
\hline Individuals identity & & \\
\hline Rate of diverse behavior & .041 & \\
\hline Total R & 260 & \\
\hline $\mathrm{N}$ &
\end{tabular}

Results of table 5.7 showed significant predicting role of average time sped using Instagram and individual's motive in social interaction, personal identity, entertainment trends and rate of diverse behavior of participants as $(p<0.005) F(11.0$, 115.5).

\section{Findings}

- In age respondent category, within the ages 20-30 the number of responses were high.

- In age respondent category, within the ages 31-50 of the number of responses were low.

- Out of total participants60\% were students.

- Respondents having high response ratio were single $80 \%$.

- Significant positive relationship was found between Instagram use and social interaction among participants during Covid-19.

- Entertainment trends become high with excessive use of Instagram.

- Average time spend using Instagram by participants were significantly predict motives behind Instagram use.

- Entertainment trends and individual's identity were found as significant predictors of Instagram use. 


\section{Discussion}

Present study found significant relationship between Instagram use and social aspects i.e. social interaction among participants using Instagram, individual identity, rate of diverse behavior, entertainment trends and updates of corona virus during pandemic situation. Use of Instagram use among adolescents and adults increased due to pandemic situation in Lahore and tend to increase needs and motives of participant's diverse behavior. Results of present study were supported by previous researches. Triani\&Vusparatih (2019) were conducted a research purposed to found the role of Instagram in creating teen's interaction, entertainment trend and personal identity of participants using Instagram. Study formulated sample of students with (age 19-22) and concluded that role of social media i.e. Instagram use as a source of information, interpersonal communication, users identity and publication entertainment in its users. Instagram use has significant positive relationship between Instagram use and social aspects of participant. Social media Instagram provides sustained information, knowledge of world, new trends and fashion and as a tool of interaction for better communication. User's behavior tend to influence by Instagram use as it provide sense of spreading and creating individuals identity and entertainment trends (Triani\&Vusparatih, 2019).

Significant positive relationship was found between information and updates of Covid-19 through the use of Instagram during lockdown situation. These results were supported by literature that quality information of transmission, causes and precaution measures of corona was declared by Instagram. A study was concluded World Health Organization affirmed the information of coronavirus outbreak using social media Instagram to give updates to people to stay safe. That information included public and private health emergencies taking steps, connectivity, social distancing and precautions from the transmission of corona virus. People using Instagram are approaching valid information. Moreover, Instagram added updates of more educational resources about symptoms and transmission of Covid-19 in Instagram search, stickers to provide valid information, only permit recommendations by health organization, promoting donation sticker in Pakistan and with other countries to help people worldwide and efforts to create and share stories of patients suffering from and those who recovered.

Average time spend in browsing Instagram daily tend to predict motives of Instagram use in participants and affect quality information, interaction, identity, fashion and entrainment trends, diverse behavior and information or corona in lock down situation. A study was conducted and formulated results supporting present finding in a way that Instagram is currently is one the most popular social media platform to educating, providing information and maintaining social interaction among adolescents and adults. More than $70 \%$ of Instagram users are adolescents and adults with age ranges 12-24 and learnt effective entertainment trends and interpersonal communication through Instagram. Average time spend in browsing Instagram daily can leads to effect quality of information and trends in Instagram and significantly predict motives behind Instagram use. The results discovered that 
time spend positively predict the motives for Instagram use were certainly browse for posts, entrainment, interaction and self-identity motives (Huang \& Su, 2018).

\section{Conclusion}

On the basis results generate through analysis of individuals responses to needs and motives of Instagram use in adults and its effects on social interaction, individual's identity, entertainment trends, diverse behavior and updates of Covid19 during pandemic situation. Significant correlation was found between Instagram use and motives of Instagram user. More the people used to browse Instagram in pandemic situation more the involved in social interactions, peer reviewing, gaining information of activities of people worldwide. Excessive use of Instagram during lockdown leads to increase people's diverse behavior and entertainments trends as they follow celebrities' outgoing behaviors, interests, and various thrilling programs. Average time spends in browsing Instagram significantly predict individuals motive of using Instagram and quality of social interaction, entertainment trends and diverse behavior of Instagram user's.

\section{Limitations of the Study}

- Present study lack to find the effects of intense Instagaram use on male and female with regards to gender differences.

- Relationship issues and many familial factors can influence an individual's behavior of using Instagram during pandemic which was not considered in present study.

- As there was lock down situation everywhere so most of participants with higher tendencies of using Instagram were not approached.

- Present study lack the qualitative responses of participants and deep interviews to measure their preferences of Instagram use rather than Facebook, Twitter and other social media networks to communicate other.

- Present study did not attempts to measure characteristics of personality that tend to influence their behavior to become part of 100 million active users with 40 million photos uploaded and shared every day on Instagram.

- Physical and psychological effects of intense Instagram use need to be reported in present research study.

\section{Suggestions/Recommendations}


Present study has following future recommendation to give a way for future findings.

- Future findings should include a physical or psychological health related variables along with social aspects of Instagram use.

- Responses of Instagram users should be explored through interviews to find subjective outcomes of the advantages of Instagram use.

- Working communities, business owners and professionals should be involved as sample of the study in future to find Instagram use effects on advertisement and business in modern times.

- Attempts to user's privacy policies and fragmentation of data using Instagram should be measured in future to evaluate its better use.

- Large number of participants should be included as sample of the study so that mediating and moderating effects of personality characteristics can be measured through Instagram use. 


\section{References}

Hamilton, J. L., Nesi, J., \&Choukas-Bradley, S. (2020, April 29). Teens and social media during the COVID-19 pandemic: Staying socially connected while physically distant. PsyArXiv.https://doi.org/10.31234/osf.io/5stx4.

Huang, T.Y., and Su, F.S. (2018).Motives for Instagram use and topics of interest among young adults.Future Internet, 10(8), 77; https:/ / doi.org/10.3390/fi10080077

Katz, E., Blumler, J. G., \&Gurevitch, M. (1973).Uses and gratifications research. The Public Opinion Quarterly, 37(4), 509-523.

Oloo, Fredrick Leica. (2013). Insta-gratification: Uses and gratification of instagram by university students for interpersonal communication. Thesis (M.A.), Eastern Mediterranean University, Institute of Graduate Studies and Research, Dept. of Communication and Media Studies, Famagusta: North Cyprus.

Reetz,M., Augustina,A., and Maryani, E. (2020, June). Public's media use and gratification sought during Corona Virus outbreak in Indonesia: A national survey.JurnalKomunikasiIkatanSarjanaKomunikasi Indonesia, Vol. 5 (1), 2020, 111124. DOI: $10.25008 /$ jkiski.v5i1.381

Rovetta, A., andBhagavathula, A. (2020, August).Global infodemiology of COVID19: Focus on Google web searches and Instagram hash tags.Journal of Medical Internet Research doi: 10.2196/20673.

Ruggiero,T. (2000).Uses and Gratifications Theory in the 21st Century.Mass Communication and Society, 3:1, 3-37, DOI: 10.1207/S15327825MCS0301_02.

Triani, D. and Vusparatih, D.S. (2019, July).The Role of Social Media Instagram in Creating Youth Trend Fashion (19-22 Years Old): Case Study of Fashion Influencer on Instagram towardsBinus University Faculty of Economics and Communication Department Students Year 2014-2017.International Journal of Scientific \& Technology Research, Volume 8, Issue 07.

Wagner,D., Marcon,A., and Caulfield,T. (2020, September).Immune boosting in the time of COVID: selling immunity on Instagram. Allergy Asthma ClinImmunol 16, 76 (2020).https:/ / doi.org/10.1186/s13223-020-00474-6.

Young, K. (1998). Caught in the net. Hoboken, NJ: John Wiley \& Sons.

Young, K. and Abreu, C. (2011).Internet addiction: A handbook and guide to evaluation and treatment. Hoboken, John Wiley \& Sons.

Yuan,Y. (2011). A survey study on uses and gratifications of social networking sites in China.MSc. Thesis.Scripps College of Communication of Ohio University. 